\title{
Fever as an important resource for infectious diseases research
}

\author{
Juan José González Plaza ${ }^{1,2, *}$, Nataša Hulak ${ }^{3}$, Zhaxybay Zhumadilov ${ }^{4}$, Ainur Akilzhanova ${ }^{4}$ \\ 'Division for Marine and Environmental Research, Ruđer Bošković Institute, Zagreb, Croatia; \\ ${ }^{2}$ Research Department, University Hospital for Infectious Diseases "Dr. Fran Mihaljević", Zagreb, Croatia; \\ ${ }^{3}$ Department of Microbiology, Faculty of Agriculture, University of Zagreb, Zagreb, Croatia; \\ ${ }^{4}$ Laboratory of Genomic and Personalized Medicine, Center for Life Sciences, PI "National Laboratory Astana", AOE \\ "Nazarbayev University", Astana, Kazakhstan.
}

\begin{abstract}
Summary Fever or pyrexia is a process where normal body temperature is raised over homeostasis conditions. Although many effects of fever over the immune system have been known for a long time, it has not been until recent studies when these effects have been evaluated in several infection processes. Results have been promising, as they have reported new ways of regulation, especially in RNA molecules. In light of these new studies, it seems important to start to evaluate the effects of pyrexia in current research efforts in host-pathogen interactions. Viruses and bacteria are responsible for different types of infectious diseases, and while it is of paramount importance to understand the mechanisms of infection, potential effects of fever on this process may have been overlooked. This is especially relevant because during the course of many infectious diseases the organism develops fever. Due to the lack of specific treatments for many of those afflictions, experimental evaluation in fever-like conditions can potentially bring new insights into the infection process and can ultimately help to develop treatments. The aim of this review is to present evidence that the temperature increase during fever affects the way the infection takes place, for both the pathogen and the host.
\end{abstract}

Keywords: Fever, infectious diseases, immune system, computational tools, RNA structure

\section{Introduction}

Fever is one of the usual clinical features that appear during the course of several infectious diseases, such as chikungunya fever caused by Chikungunya virus (CHIKV) (1), Hantavirus Pulmonary Syndrome (HPS) (2) or Hemorrhagic Fever with Renal Syndrome (HFRS) $(3,4)$ caused by several members of the Hantavirus (HTV) genus, uncomplicated malaria fever caused by Plasmodium falciparum infection (5), enteric fever caused by Salmonella serovars (6), cat scratch fever caused by Bartonella spp. (7), or is a common symptom in infants or adolescents affected by pulmonary tuberculosis due to Mycobacterium tuberculosis infection

Released online in J-STAGE as advance publication April 25, 2016.

*Address correspondence to:

Dr. Juan José González Plaza, Division for Marine and Environmental Research, Ruđer Bošković Institute, Bijenička 54, P.O. Box 180, 10002 Zagreb, Croatia.

E-mail:plaza@irb.hr
(8), among other type of infectious diseases. It is also a symptom that helps to recognize disease (9).

In order to develop new applications which could potentially serve as treatments, we need to increase our knowledge on the way that host-pathogen interaction works. Although there are many excellent efforts in this regard, an aspect that has not been broadly experimentally addressed has been the potential implications of fever on the interaction with the host and the development of the infection. Some studies have shown the importance of these types of considerations when evaluating hyperthermic incubation conditions compared with the homeostasis temperature of $37^{\circ} \mathrm{C}(10)$. Therefore this review will focus on fever as an important variable to be considered in infectious diseases research, focusing especially on studies that reported how pyrexia can affect on the one hand the host immune response (11), and on the other hand the pathogen response.

\section{Acquisition of fever during evolution}

The acquisition of mechanisms to regulate body 
temperature has been an evolutionary achievement for homeothermic and later endothermic organisms (12), in order to gain freedom and occupy different environmental niches, and it is translated as a notable degree of independence from environmental fluctuations (13). Within the regulation of body temperature, a further specialization has been the development of fever during certain conditions, among them infections caused by pathogens. Although it is still a matter of debate if this response represents an advantage for the host or is deleterious (9), the fact that fever is a costly process for metabolism indicates that it may have been conserved due to an evolutionary advantage (14). As indicated by Harden et al. (9), there is a growing body of evidence to sustain the view that fever is beneficial for the host $(15,16)$. Recently, Earn et al. (17) have found that suppression of fever in normal clinical settings can potentially lead to negative effects at the populationlevel, due to a possible increase in the spread of associated infections.

Fever is a process in which the body temperature rises, deviating from normal values $(7,18)$, and according to the excellent scientific text of Saladin (18), it is a beneficial process as long as it does not persist, or reaches $44^{\circ} \mathrm{C}$ to $46^{\circ} \mathrm{C}$, where it could be fatal or lead to irreversible brain damage. For further information about its origin, control, and implications on the immune response we strongly encourage the reader to consult the above mentioned source (18).

\subsection{Effect of fever over the pathogen}

As well as human microbiota (19), pathogens have coexisted with their hosts for a long time during evolution, and they have developed mechanisms especially adapted to circumvent immunological barriers (20). Regarding temperature changes, bacteria have developed strategies to adapt to these variations in the environment (21), and similar strategies could be found in pathogenic ones (22). One of the first phases for a pathogen during the infection process would be to sense when they are within the host (22). Body temperature $\left(37^{\circ} \mathrm{C}\right)$ acts as a signal for transcriptomic changes in Histoplasma capsulatum $(H c)$ (23). As these authors have demonstrated that homeostatic temperature of the host is capable of inducing changes in the transcriptomic landscape of the pathogen, it could be consequently thought that infectious agents have probably adapted to develop a response when fever appears. Morita et al. (24) highlighted a mechanism of temperature sensing in Escherichia coli, through the secondary structure of mRNA, where ribosome binding is facilitated at higher temperatures. In keeping with these suggestions Loh et al. (25) described an effect of temperature (such as pyrexia) in immune evasion by the pathogen Neisseria meningitidis. The pathogen is able to detect increases in temperature through RNA thermosensors, that leads to expression of mechanisms to avoid the host immune responses that are triggered during fever. In another set of experiments, Eldahad et al. (6) have demonstrated that 3 different typhoidal serovars from Salmonella enterica are affected at fever-like temperatures, several infective features are impaired, and that fever could be used by the pathogen as a signal to enter into a phase of persistence in the organism. Moreover, fever temperatures in vitro inhibited the growth of the protozoan parasite Plasmodium falciparum (5). In the case of viruses, high temperature have been demonstrated to destabilize viral RNA polymerase in highly pathogenic avian influenza (HPAI) $(26,27)$, or can exert an inhibitory effect over the synthesis of the viral RNA genome of Human Influenza A virus (28).

These studies open the door for the evaluation of molecular changes on the pathogen in an environment where temperature increases, especially over gene expression, and conformational changes that may affect RNA structures (as shown for thermosensors), or efficiency of the viral replication machinery.

\subsection{Effects of fever on the immune system}

Increase of temperature within the host has also an impact over the immune system (29), demonstrated by Murdock et al. (30), where they report that temperature can impact mosquito (Anopheles stephensi Liston) immunity. In humans, Tomiyama et al. (11) have evaluated the effect of mild hyperthermia treatment on healthy adults, reporting an enhancement of innate and adaptive immunity. Another study focused on the characterization of the response of Dendritic Cells (DCs) to Aspergillus fumigatus at two different temperatures (homeostasis at $37^{\circ} \mathrm{C}$, and fever-like temperature at $40^{\circ} \mathrm{C}$ ), having found no differences in DC viability or cytokine release, but a higher maturation rate for DCs and a lower phagocytic capacity at $40^{\circ} \mathrm{C}(31)$. Further characterization of the influence of feverlike temperatures on mice DCs (15) found an effect of higher temperatures on the maturation of these cells. DCs are precisely one cell type, with macrophages, that are activated to unchain a series of events that leads to a systemic induction of fever when infection occurs (29). It is then that the same cells, which are key to the febrile process, are ultimately affected by fever in their immunological features.

Fever has been demonstrated to affect other immune cells as reflected by Harden et al. $(9,32)$, including different types as neutrophils, monocytes or T-cells, or Natural Killer cells (NK) (29) as well.

It has been highlighted (18) that enzymatic reactions may race ahead during a period with higher temperatures, further explained by Fields et al. (33) (view section 3). In the sense indicated in (29), fever is a product of one or several biological processes, where the detection of pathogen unchains a set of events that end up in a fever 
process, that plays in favor of the host.

\section{Molecular consequences during fever: a theory}

Increases of temperature have an impact on biological processes in living systems, with several well documented examples. It has been demonstrated in plants that heat shock is responsible for blocking mature ribosome production $(34,35)$, which are key organelles for the normal performance of the entire cell and ultimately the whole organism (36). Higher temperatures induce physiological processes in the body such as sweating (that essentially have a molecular origin/response), as one of the mechanisms to dissipate heat (37).

At a deeper molecular level, heat-shock proteins (HSPs) $(38,39)$, are a set of genetically conserved stress sensitive proteins (39) that accumulate in cases of exposure to high temperatures $(35,40-43)$, among other sets of stressful conditions, in order to protect the cell (44), potentially by aiding in correct folding of proteins denatured by heat shock $(35,45)$. They have been described in a range of species $(40,44,46)$, including vertebrates (41) and among those, humans (47). Lack of the 70-kilodalton family of HSPs (HSP70), a highly conserved protein promoter of heat tolerance (46), induces heat shock sensitivity in $E$. coli strains that would be otherwise resistant to that type of stress. For humans and rodents, short in vitro exposure to the range of 41$43^{\circ} \mathrm{C}$ induces heat shock, leading to induction of HSPs synthesis (48). Heat shock is connected with immune response mediators, such as cytokines (48). HSPs have an important role for the host immune response as well as for the pathogen mechanisms of evasion. From the point of view of the pathogen, overexpression of HSP70 and HSP60 are fundamental for the survival of Salmonella typhimurium during macrophage infection $(46,49,50)$. Besides, within the host they can act as antigen carriers, although not as direct activators of the innate immune response (51).

Temperature has the capability to influence membrane fluidity, as it has been described in plants through the modification of the saturation pattern of the fatty acid component of membrane lipids (52). The effect of a temperature decrease will lead to lowered fluidity (e.g. oils in nature get solid when reaching a certain temperature), while higher temperatures increase lipid fluidity (53-55); and temperature also has a direct impact on the ion transport systems in frog erythrocytes (56). Because fluidization can have negative consequences for the cell at very high temperatures (57), there is a higher content of saturated fatty acids displayed in that set of stressful conditions to maintain cell function and integrity (55). Further stabilization of the membrane structure is achieved through participation of cholesterol (58). All of the above has important consequences for infectious diseases, as the cell membrane is one of the first contact surfaces with the external environment. Cholesterol is also one of the key components of membrane lipid rafts $(59,60)$, which are used by a number of pathogens as an entry point (58) due to the abundance of potential receptors for the pathogen. Amini-Bavil-Olyaee have found that an indirect disturbance of intracellular cholesterol homeostasis is capable of interfering with viral entry (60). In keeping with those results, Kapadia and Chisari showed that Hepatitis $\mathrm{C}$ virus (HCV) RNA replication relies on the host biosynthetic pathways of cholesterol and fatty acids. Phenothiazines have been used to target and increase fluidity leading to inhibition of HCV entry (61); while drugs that inhibited hostmembrane fluidity elevated mortality in mice treated with normally mild influenza A virus (IAV) infection (62). These and other findings are pointing to lipid membranes as very interesting targets for treatment of infectious diseases, or to tackle antimicrobial resistance (63). Although we are considering an increase of temperature from the homeostasis point of $37^{\circ} \mathrm{C}$, to 40 $41^{\circ} \mathrm{C}$, that deviation from normality can lead to the above mentioned perturbations in terms of HSPs expression or in membrane fluidity through fatty acid composition or permeability, and that can have consequences for the infection process, as has been previously highlighted. The remaining question is if this deviation of a few degrees would translate into changes in the structure or the activity of proteins, such as enzymes (64), in a way that they cannot perform their normal functions, or push ahead cellular metabolism (33). Enzymes can display sensitivity to temperature, and this can be transferred to the biochemical process in which they take part (33). Additionally, the rate of a reaction has an exponential relationship with the temperature (33). In this scenario recent efforts have evaluated the metabolomic profile during a transitional fever process in order to understand better the biochemical basis in rats (65). These type of experimental approaches are appropriate as many metabolic reactions are affected by temperature (33), and the generated information has great potential to aid in understanding the overall infection process.

\section{Computational tools to analyze fever effects}

In order to evaluate potential effects of fever on the pathogen RNA secondary structure, computational approaches can be used. It can be hypothesized that some pathogens may be changing their behaviour during pyrexia due to different properties of their RNA molecules, or that bacterial pathogens may have some type of RNA thermosensors which have not been described yet. It is known that RNA are not linear molecules, and have complex tridimensional structures that may be affected by temperature, as shown for RNA thermosensors/thermometers $(66,67)$. RNA thermometers follow changes in their structure upon temperature variation (68), with the capability of even 
sensing changes down to $1^{\circ} \mathrm{C}(69)$. They importantly control virulence factors in bacteria $(70,71)$.

The use of computational tools to evaluate in a first step potential temperature-induced perturbations of the secondary structure of RNA in different viruses or bacteria, seems like a reasonable approach prior to experimental evaluation. These changes in the structure would appear as a consequence of the increase of temperature that occurs in inflammation processes upon infection. Potential changes can be evaluated using RNAtips (72), a user-friendly tool for the evaluation of temperature-driven perturbations in RNA structure, and which was developed by Chursov and colleagues (72). For an evaluation of the fever, the temperature range can be set from $37^{\circ} \mathrm{C}$ to $41^{\circ} \mathrm{C}$. Another type of analysis can be performed with the RNAfold web server $(73,74)$ in order to generate plots for the Minimum Free Energy (MFE ) or the centroid secondary structure, as an example, to evaluate the influence of temperature over the structure, at either $37^{\circ} \mathrm{C}$ or $40^{\circ} \mathrm{C}$.

These are two types of computational tools that can be used to carry out in silico simulations in order to evaluate how feasible it would be to perform this experimental approach. Due to the current advances in sequence information for many infective agents, we strongly encourage the scientific community to evaluate potential changes in the secondary structure of RNA as a first step towards further experimental studies.

\section{Conclusions}

The usual growth temperature when carrying out in vitro cultures using cells from human, mouse, or other mammals, is normally $37^{\circ} \mathrm{C}$, in order to mimic the biological conditions of these species (regarding their body temperature). In the field of infectious diseases, the in vitro interaction between the host and the pathogen is also evaluated at $37^{\circ} \mathrm{C}$. This information is of paramount importance to better understand the interaction process. However, as in vitro interaction experiments are not performed at fever-like temperatures (from $39^{\circ} \mathrm{C}$ to $41^{\circ} \mathrm{C}$ ), we are losing valuable data. Fever is an overall beneficial process for the host although it is energetically costly. Pathogens have developed an array of tools that allow them to adapt to the host, such as RNA thermometers, to sense when they are within the host in order to express virulence genes, or to enter in a state of dormancy. Fever has an impact over diverse types of pathogens, such as bacteria, viruses, or parasites. As well, the host is affected by febrile processes in its immune system, as shown for different host species such as moquitoes or humans. Those increases in temperature in the range of a few degrees induce changes at different biological levels: in the behaviour of DCs, in the developmental programmes of parasites, in the virulence factors of bacteria, and in the tridimensional structure of RNAs (a set of them, called RNA thermometers)
$(67,69,75,76)$.

At a molecular level, fever affects cells by the induction of HSPs expression, a set of evolutionarily conserved proteins. Cellular membranes are key elements in the entry of several pathogens, as demonstrated for viruses. In that process key aspects such as lipid composition or fluidity can be directly affected by pyrexia. Enzymatic reactions are also dependent on temperature, and there is a potential impact of fever on normal metabolic flux. Taking into account all of the discoveries in the field until now, infectious disease research can benefit enormously by considering fever as a key element for the development of the infection process. The value of these kind of experiments at feverlike temperatures is that a better understanding of the infection process can be achieved, observing if fever has a negative impact over the pathogen, or if it increases its virulence. Ultimately, this information can help in the development of new treatments for intractable diseases, or to manage fever differently in clinical settings.

\section{Acknowledgements}

JG and NH are both currently supported by postdoctoral fellowships from the Croatian Science Foundation (Hrvatska Zaklada za Znanost). This study was supported by a grant (Innate Immunity to Hantaviruses, HANTAINNATE) from the Croatian Science Foundation. The authors regret that very important work in the field could not be acknowledged due to space limitations.

\section{References}

1. Staples JE, Breiman RF, Powers AM. Chikungunya fever: An epidemiological review of a re-emerging infectious disease. Clin Infect Dis. 2009; 49:942-948.

2. MacNeil A, Nichol ST, Spiropoulou CF. Hantavirus pulmonary syndrome. Virus Res. 2011; 162:138-147.

3. Berk H, Öztoprak N. Hemorrhagic fever with renal syndrome (Hantaviruses). J Microbiol Infect Dis. 2014; 4:S41-49.

4. Avšič Županc T, Korva M, Markotić A. HFRS and hantaviruses in the Balkans/South-East Europe. Virus Res. 2014; 187:27-33.

5. Kwiatkowski D. Tumour necrosis factor, fever and fatality in falciparum malaria. Immunol Lett. 1990; 25:213-216.

6. Elhadad D, McClelland M, Rahav G, Gal-Mor O. Feverlike Temperature is a virulence regulatory cue controlling the motility and host cell entry of typhoidal Salmonella. J Infect Dis. 2015; 212:147-156.

7. Ogoina D. Fever, fever patterns and diseases called "fever" - A review. J Infect Public Health. 2011; 4:108124.

8. Cruz AT, Starke JR. Clinical manifestations of tuberculosis in children. Paediatr Respir Rev. 2007; 8:107-117

9. Harden LM, Kent S, Pittman QJ, Roth J. Fever and sickness behavior: Friend or foe? Brain Behav Immun. 2015; 50:322-333. 
10. Blauenfeldt $\mathrm{T}$, Wagner D, Aabye M, et al. Thermostability of IFN- $\gamma$ and IP-10 release assays for latent infection with Mycobacterium tuberculosis: A TBnet study. Tuberculosis. 2016; 98:7-12.

11. Tomiyama C, Watanabe M, Honma T, Inada A, Hayakawa T, Ryufuku M, Abo T. The effect of repetitive mild hyperthermia on body temperature, the autonomic nervous system, and innate and adaptive immunity. Biomed Res. 2015; 36:135-142.

12. Clarke A, Pörtner H-O. Temperature, metabolic power and the evolution of endothermy. Biol Rev. 2010; 85:703-727.

13. Angilletta MJ Jr, Cooper BS, Schuler MS, Boyles JG. The evolution of thermal physiology in endotherms. Front Biosci (Elite Ed). 2010; 2:861-881.

14. Young PJ, Saxena M. Fever management in intensive care patients with infections. Crit Care. 2014; 18:206.

15. Tournier J-N, Hellmann AQ, Lesca G, Jouan A, Drouet E, and Mathieu J. Fever-like thermal conditions regulate the activation of maturing dendritic cells. J Leukoc Biol. 2003; 73:493-501.

16. El-Radhi ASM. Fever management: Evidence $v s$. current practice. World J Clin Pediatr. 2012; 1:29-33.

17. Earn DJD, Andrews PW, Bolker BM. Populationlevel effects of suppressing fever. Proc R Soc. 2014; 281:20132570.

18. Saladin K. Major themes on anatomy and physiology. In: Anatomy \& Physiology: The Unity of Form and Function (6th Edition). McGraw-Hill, NY, USA, 2011; pp. 1-27.

19. Dethlefsen L, McFall-Ngai M, Relman DA. An ecological and evolutionary perspective on humanmicrobe mutualism and disease. Nature. 2007; 449:811818.

20. Finlay BB, McFadden G. Anti-immunology: Evasion of the host immune system by bacterial and viral pathogens. Cell. 2006; 124:767-782.

21. Schumann W. Temperature sensors of eubacteria. Adv Appl Microbiol. 2009; 67:213-256.

22. Shapiro RS, Cowen LE. Thermal control of microbial development and virulence: Molecular mechanisms of microbial temperature sensing. MBio. 2012; 3:e023812.

23. Gilmore SA, Voorhies M, Gebhart D, Sil A. Genomewide reprogramming of transcript architecture by temperature specifies the developmental states of the human pathogen histoplasma. PLoS Genet. 2015; 11:e1005395.

24. Morita M, Kanemori M, Yanagi H, Yura T. Heatinduced synthesis of $\sigma 32$ in Escherichia coli: Structural and functional dissection of rpoH mRNA secondary structure. J Bacteriol. 1999; 181:401-410.

25. Loh E, Kugelberg E, Tracy A, Zhang Q, Gollan B, Ewles H, Chalmers R, Pelicic V, Tang CM. Temperature triggers immune evasion by Neisseria meningitidis. Nature. 2013; 502:237-240.

26. Scholtissek C, Rott R. Effect of temperature on the multiplication of an influenza virus. J Gen Virol. 1969; 5:283-290.

27. Alexander DJ, Brown IH. Recent zoonoses caused by influenza A viruses. Rev Sci Tech. 2000; 19:197-225.

28. Dalton RM, Mullin AE, Amorim MJ, Medcalf E, Tiley LS, Digard P. Temperature sensitive influenza A virus genome replication results from low thermal stability of polymerase-cRNA complexes. Virol J. 2006; 3:58.
29. Evans SS, Repasky EA, Fisher DT. Fever and the thermal regulation of immunity: The immune system feels the heat. Nat Rev Immunol. 2015; 15:335-349.

30. Murdock CC, Paaijmans KP, Bell AS, King JG, Hillyer JF, Read AF, Thomas MB. Complex effects of temperature on mosquito immune function. Proc R Soc. 2012; 279:3357-3366.

31. Semmlinger A, Fliesser M, Waaga-Gasser AM, Dragan M, Morton CO, Einsele H, Loeffler J. Fever-range temperature modulates activation and function of human dendritic cells stimulated with the pathogenic mould Aspergillus fumigatus. Med Mycol. 2014; 52:438-444.

32. Blatteis CM. Fever: Pathological or physiological, injurious or beneficial? J Therm Biol. 2003; 28:1-13.

33. Fields PA, Dong Y, Meng X, Somero GN. Adaptations of protein structure and function to temperature: There is more than one way to "skin a cat." J Exp Biol. 2015; 218:1801-1811.

34. Scharf K-D, Nover L. Control of ribosome biosynthesis in plant cell cultures under heat shock conditions. II. Ribosomal proteins. Biochim Biophys Acta. 1987; 909:44-57.

35. Lindquist S, Craig EA. The heat-shock proteins. Annu Rev Genet. 1988; 22:631-677.

36. Dahlberg AE. The functional role of ribosomal RNA in protein synthesis. Cell. 1989; 57:525-529.

37. Shibasaki M, Wilson TE, Crandall CG. Neural control and mechanisms of eccrine sweating during heat stress and exercise. J Appl Physiol. 2006; 100:1692-1701.

38. Moseley PL. Heat shock proteins and heat adaptation of the whole organism. J Appl Physiol. 1997; 83:14131417.

39. Kregel KC. Heat shock proteins: Modifying factors in physiological stress responses and acquired thermotolerance. J Appl Physiol. 2002; 92:2177-2186.

40. Merkling SH, Overheul GJ, van Mierlo JT, Arends D, Gilissen C, van Rij RP. The heat shock response restricts virus infection in Drosophila. Sci Rep. 2015; 5:12758.

41. Xie Y, Song L, Weng Z, Liu S, Liu Z. Hsp90, Hsp60 and sHsp families of heat shock protein genes in channel catfish and their expression after bacterial infections. Fish Shellfish Immunol. 2015; 44:642-651.

42. Ritossa F. A new puffing pattern induced by temperature shock and DNP in Drosophila. Experientia. 1962; 18:571-573.

43. Srivastava P. Roles of heat-shock proteins in innate and adaptive immunity. Nat Rev Immunol. 2002; 2:185-194.

44. Knight M, Elhelu O, Smith M, Haugen B, Miller A, Raghavan N, Wellman C, Cousin C, Dixon F, Mann V, Rinaldi G, Ittiprasert W, Brindley PJ. Susceptibility of snails to infection with schistosomes is influenced by temperature and expression of heat shock proteins. Epidemiology (Sunnyvale). 2015; 5. pii:189.

45. Beckmann RP, Mizzen LE, and Welch WJ. Interaction of Hsp 70 with newly synthesized proteins: Implications for protein folding and assembly. Science. 1990; 248:850854.

46. Rey-Ladino J, Senok A, Sarkar A, Al Shedoukhy A. The role of heat shock protein 70 in infection and immunity. In: Heat Shock Protein-Based Therapies (Asea AAA, Almasoud NN, Krishnan S, Kaur P, eds.). Springer International Publishing, Cham, Switzerland, 2015; pp. 95-117.

47. Klingspor S, Bondzio A, Martens H, Aschenbach JR, Bratz K, Tedin K, Einspanier R, Lodemann U. Enterococcus 
faecium NCIMB 10415 modulates epithelial integrity, heat shock protein, and proinflammatory cytokine response in intestinal cells. Mediators Inflamm. 2015; 2015:304149.

48. Polla BS. A role for heat shock proteins in inflammation? Immunol. Today. 1988; 9:134-137.

49. Garbe TR. Heat shock proteins and infection: interactions of pathogen and host. Experientia. 1992; 48:635-639.

50. Buchmeier NA, Heffron F. Induction of Salmonella stress proteins upon infection of macrophages. Science. 1990; 248:730-732.

51. Bausinger H, Lipsker D, Hanau D. Heat-shock proteins as activators of the innate immune system. Trends Immunol. 2002; 23:342-343.

52. Murata N, Los DA. Membrane fluidity and temperature perception. Plant Physiol. 1997; 115:875-879.

53. Chapman D. Phase transitions and fluidity characteristics of lipids and cell membranes. Q Rev Biophys. 1975; 8:185-235

54. Hazel JR. Thermal adaptation in biological membranes: Is homeoviscous adaptation the explanation? Annu Rev Physiol. 1995; 57:19-42.

55. Guyot S, Gervais P, Young M, Winckler P, Dumont J, Davey HM. Surviving the heat: Heterogeneity of response in Saccharomyces cerevisiae provides insight into thermal damage to the membrane. Environ Microbiol. 2015; 17:2982-2992.

56. Agalakova NI, Lapin A V, Gusev GP. Temperature effects on ion transport across the erythrocyte membrane of the frog Rana temporaria. Comp Biochem. Physiol Part A Physiol. 1997; 117:411-418.

57. Los DA, Murata N. Membrane fluidity and its roles in the perception of environmental signals. Biochim Biophys Acta. 2004; 1666:142-157.

58. Sviridov D, Bukrinsky M. Interaction of pathogens with host cholesterol metabolism. Curr Opin Lipidol. 2014; 25:333-338.

59. Simons K, Ehehalt R. Cholesterol, lipid rafts, and disease. J Clin Invest. 2002; 110:597-603.

60. Amini-Bavil-Olyaee S, Choi YJ, Lee JH, Shi M, Huang I-C, Farzan M, Jung JU. The antiviral effector IFITM3 disrupts intracellular cholesterol homeostasis to block viral entry. Cell Host Microbe. 2013; 13:452-464.

61. Chamoun-Emanuelli AM, Pecheur E-I, Simeon RL, Huang D, Cremer PS, Chen Z. Phenothiazines inhibit hepatitis $\mathrm{C}$ virus entry, likely by increasing the fluidity of cholesterol-rich membranes. Antimicrob Agents Chemother. 2013; 57:2571-2581.

62. Lin T-Y, Chin CR, Everitt AR, Clare S, Perreira JM, Savidis G, Aker AM, John SP, Sarlah D, Carreira EM, Elledge SJ, Kellam P, Brass AL. Amphotericin B Increases Influenza A Virus Infection by Preventing IFITM3Mediated Restriction. Cell Rep. 2013; 5:895-908.

63. Mingeot-Leclercq M-P, Décout J-L. Bacterial lipid membranes as promising targets to fight antimicrobial resistance, molecular foundations and illustration through the renewal of aminoglycoside antibiotics and emergence of amphiphilic aminoglycosides. Med Chem Commun. 2016; DOI: 10.1039/c5md00503e.

64. Alberts B, Johnson A, Lewis J, Raff M, Roberts K, Walter P. Protein Function. 4th edn. Mol Biol Cell. Garland Science, NY, USA, 2002.

65. Liu H, Zhang L, Zhao B, Zhang Z, Qin L, Zhang Q, Wang Q, Lu Z, Gao X. Hypothalamus metabolomic profiling to elucidate the tissue-targeted biochemical basis of febrile response in yeast-induced pyrexia rats. Chem Biol Interact. 2015; 231:61-70.

66. Righetti F, Narberhaus F. How to find RNA thermometers. Front Cell Infect Microbiol. 2014; 4:132.

67. Krajewski SS, Narberhaus F. Temperature-driven differential gene expression by RNA thermosensors. Biochim Biophys Acta. 2014; 1839:978-988.

68. Narayan S, Kombrabail MH, Das S, Singh H, Chary KVR, Rao BJ, Krishnamoorthy G. Site-specific fluorescence dynamics in an RNA "thermometer" reveals the role of ribosome binding in its temperature-sensitive switch function. Nucleic Acids Res. 2014; 43:493-503.

69. Rinnenthal J, Klinkert B, Narberhaus F, Schwalbe H. Direct observation of the temperature-induced melting process of the Salmonella fourU RNA thermometer at base-pair resolution. Nucleic Acids Res. 2010; 38:38343847.

70. Lam O, Wheeler J, Tang CM. Thermal control of virulence factors in bacteria: A hot topic. Virulence. 2014; 5:852-862.

71. Grosso-Becera MV, Servín-González L, Soberón-Chávez G. RNA structures are involved in the thermoregulation of bacterial virulence-associated traits. Trends Microbiol. 2015; 23:509-518.

72. Chursov A, Kopetzky SJ, Bocharov G, Frishman D, and Shneider A. RNAtips: Analysis of temperature-induced changes of RNA secondary structure. Nucleic Acids Res. 2013; 41:W486-491.

73. Lorenz R, Bernhart SH, Höner zu Siederdissen C, Tafer H, Flamm C, Stadler PF, and Hofacker IL. ViennaRNA Package 2.0. Algorithms Mol Biol. 2011; 6:26.

74. Gruber AR, Lorenz R, Bernhart SH, Neuböck R, Hofacker IL. The vienna RNA websuite. Nucleic Acids Res. 2008; 36:W70-74.

75. Krajewski SS, Nagel M, Narberhaus F. Short ROSElike RNA thermometers control IbpA synthesis in Pseudomonas species. PLoS One. 2013; 8:e65168.

76. Saragliadis A, Krajewski SS, Rehm C, Narberhaus F, Hartig JS. Thermozymes: Synthetic RNA thermometers based on ribozyme activity. RNA Biol. 2013; 10:10091016.

(Received February 16, 2016; Revised March 26, 2016; Accepted April 4, 2016) 